To appear in the International Journal of Production Research

Vol. 00, No. 00, 00 Month 20XX, 1-29

\title{
Optimal replenishment cycle for perishable items facing demand uncertainty in a two-echelon inventory system
}

\author{
(Received 00 Month 20XX; accepted 00 Month 20XX)
}

\begin{abstract}
We consider a two-echelon supply chain with an upstream manufacturer and a downstream retailer for a single perishable product. The manufacturer processes raw materials into finished products, which are purchased by the retailer in each replenishment cycle. The raw materials of the manufacturer are highly perishable (i.e., perishing within hours or days), and the finished goods at the retailer face demand uncertainty and obsolescence. We model the manufacturer-retailer relationship as a Stackelberg game where the retailer is the leader and decides the replenishment cycle that minimizes its mismatch cost between supply and uncertain demand. The manufacturer is the follower and decides its processing rate to minimize its unit cost for finished goods. Our results show that the raw material and finished goods lifetimes, which are interrelated through the duration of the replenishment cycle, have a significant impact on supply chain costs. Although raw material spoilage cost by itself is low, we show that short raw material lifetimes have a significant impact on the costs of both parties. Additionally, we find that while high manufacturer markups increase retailer costs, they reduce the manufacturer's costs due to large production batches.
\end{abstract}

Keywords: Inventory control, uncertainty modeling, perishability, Stackelberg game

\section{Introduction}

Perishable products account for over $40 \%$ of sales in grocery chains (Buck and Minvielle 2014). Factors such as limited lifetime, high safety and quality requirements, together with short lead time requirements make them highly complex to manage. For retailing only, losses can be up to 15 percent due to damage and spoilage (Buck and Minvielle 2014; Ferguson and Ketzenberg 2006). In the US alone, spoilage amounted to $\$ 500$ million in 2003 according to The Grocery Manufacturers of America (GMA)(Karaesmen, Scheller-Wolf, and Deniz 2011). Worldwide, of all the food produced in the food supply chain (Kummu et al. 2012), around $24 \%$ is wasted in terms of kcals.

Rising consumer awareness on the resource-intensity of production and environmental consequences of food waste have led benchmarking systems such as the Dow Jones Sustainability Index 
to include waste generation as an important key performance indicator in the assessment of firms' environmental performance. Today, leading food manufacturers such as Nestlé and Unilever explicitly include waste elimination in their firm policies and targets (Kırc1 and Seifert 2015). Yet, reducing waste usually depends on the operations of multiple supply chain entities. These entities make their decisions in the supply chain interdependently to avoid supply-demand mismatches and reduce spoilage.

Our model is motivated by products such as processed dairy products or fruit juices. Ingredients of such products typically have a short raw material lifetime. The raw materials undergo processing and are turned into finished goods. This procedure increases their lifetime due to sterilization and added preservatives. Our objective is to analyze operational and spoilage costs in a manufacturerretailer setting for perishable products with uncertain demand. We are particularly interested in replenishment cycles, that largely influence logistics and handling costs, product freshness, as well as spoilage. This paper is an extension of the research in the doctoral dissertation by Kirc1 (2017).

We use a Stackelberg model where both parties want to reduce their own costs, and the retailer is the leader. This situation is applicable to many developed countries, where grocery sales are dominated by powerful retailers that have large customer bases. For example, Walmart has a strong bargaining power over its suppliers and can often squeeze the profits of their suppliers (Riper 2004). At the center of this research are the following questions:

- What is the optimal replenishment cycle that minimizes the retailer's mismatch and shelfspace costs under demand uncertainty and finished goods perishability?

- What is the optimal production rate that minimizes the manufacturer's raw material spoilage costs for a given replenishment cycle?

- What is the relationship between the manufacturer's and the retailer's costs?

There is a lack of studies that focus on both the raw material and finished goods perishability in a two-stage supply chain model. This research contributes to the existing literature on perishable inventory under demand uncertainty by analyzing the impact of raw material and finished goods spoilage on supply chain costs. Moreover, we consider the replenishment cycle as an endogenous variable, and find the optimal replenishment cycle for a two-echelon supply chain.

Our results show that the operations of the manufacturer and the retailer are highly interrelated through the replenishment cycle and the selling price of the manufacturer. We find that the disposal cost of a spoiled raw material may not significantly impact the costs in the supply chain. 
Nevertheless, the lifetimes of raw materials and finished goods have a significant influence on supply chain costs. We also show that short finished goods lifetimes may lead to suboptimal replenishment cycles. An increase in the unit production cost entices the manufacturer to produce products with longer lifetimes in its product portfolio. Retailers are incentivized to influence the manufacturer's markup and raw-material-sourcing decisions to better coordinate the supply chain.

The remainder of the paper is organized as follows. In Section 2 we review the literature on inventory control policies and how they relate to replenishment frequencies. In Section 3 we describe the problem in general terms. In Sections 4.1 and 4.2 we analyze the retailer's and the manufacturer's problem, respectively. In Section 5 we provide a numerical analysis to complement our analytical results, and we discuss the managerial insights. In Section 6 we provide concluding remarks and suggest future research directions.

\section{Literature review}

Our model is related to supply chain inventory models with perishability and demand uncertainty, in particular for food supply chains. Perishable inventory models have been studied by scholars since the 1960s, and are motivated by applications to fresh food, blood banks, meat, chemicals, composite materials and pharmaceutical products (Gürler and Özkaya 2008). Extensive reviews of this literature stream include Nahmias (1982), Raafat (1991), Goyal and Giri (2001), Karaesmen, Scheller-Wolf, and Deniz (2011) and Bakker, Riezebos, and Teunter (2012).

One research stream in the extant literature focuses on the operational dynamics of perishable products in a single-echelon setting. Minner and Transchel (2010) present a method to determine dynamic order quantities for fresh food and show that a constant-order policy might provide good results under stationary demand, short shelf-life, and LIFO inventory depletion. Reiner, Teller, and Kotzab (2013) study in-store logistics processes for handling dairy products, and find that strategic and tactical design of in-store logistics processes leads to higher on-shelf availability and reduced obsolescence costs. Huang (2013) uses an economic ordering model with lognormal demand to find optimal order quantities for retailers. Kouki et al. (2016) investigate the impact of perishability for a continuous review can-order policy to coordinate multiple items with random lifetimes. GutierrezAlcoba et al. (2017) study the lot sizing problem to derive the expected value of perishable inventory of different ages. Nakandala, Lau, and Shum (2017) show the effects of lateral transshipment on perishable inventory costs. 
In another research stream, scholars investigate the strategic aspects of inventory control of perishable products in a multi-echelon setting. Ferguson and Ketzenberg (2006) study the impact of information sharing about product age on a retailer's profit in the grocery industry and show that the benefits are highest when demand variability and costs are high, and product lifetimes are short. Ketzenberg and Ferguson (2008) analyze a two-stage serial supply chain and compared decentralized information (whereby the supplier and retailer maximize their profits independently) to a centralized control structure where replenishment decisions are coordinated. Cai et al. (2010) optimize orders and prices for distributors and retailers of groceries, and show that coordination can benefit both parties. Wu, Shen, and Zhu (2015) model transportation economies of scale for perishable items in a network with a single supplier and multiple retailers.

In the extant literature on the inventory management of perishable products, scholars either focus on the operational aspects (e.g., optimization of ordering policy) in detail in a single-echelon setting or on strategic aspects (e.g., information sharing mechanisms) in a multi-echelon setting. We develop a Stackelberg model to analyze the operational dynamics in detail in a two-echelon setting.

The Stackelberg model has been extensively used in operations management literature to model supply chain decisions with multiple echelons (Pasternack 1985; Choi 1991; Kadiyali, Chintagunta, and Vilcassim 2000; Barnes-Schuster, Bassok, and Anupindi 2002; René and Wein 2003; Savaskan, Bhattacharya, and Van Wassenhove 2004; Yu et al. 2013). In these studies, either the retailer or the manufacturer is the Stackelberg leader. We set the retailer as the leader, considering examples such as Walmart in the US (Riper 2004), or Migros in Switzerland (Kırc1, Isaksson, and Seifert 2017). Unlike prior studies which mainly optimize prices, our principal decision variables are the replenishment cycle of the retailer and the production rate of the manufacturer to minimize their respective costs.

Our model differs from previous models such that we consider both raw material and finished goods perishability. We use a queuing model to solve the optimal processing rate of the manufacturer to reduce raw material perishability. We further solve the optimal replenishment frequency, by including finished goods perishability constraints. Moreover, we conceptualize the manufacturer's and the retailer's relationship as a Stackelberg competition, with the retailer being the leader. A major departure from earlier research is that we consider the replenishment cycle as an endogenous variable, and adjust the order quantities accordingly. 


\section{Problem description}

We consider a perishable inventory system with a single manufacturer and a single retailer, with raw material perishability and finished goods obsolescence. The manufacturer and retailer want to sign a contract at the beginning of a time horizon of length $L$. With this contract, they want to specify the replenishment cycle $T$ (i.e., the time between two deliveries) and the order quantity $S(T)$ over the total time horizon $L$. Hence, in every constant replenishment cycle $T$ within this time horizon, the manufacturer delivers a quantity of finished products $S(T)$ to the retailer. We model this relationship as a Stackelberg game where the retailer is the leader and the manufacturer is the follower, as in previous studies stated in Section 2. We use the example of Walmart (Riper 2004) as a motivating example for a dominant retailer who have a high bargaining power with suppliers.

The sequence of events is depicted in Figure 1. At each cycle, the manufacturer receives raw materials with a Poisson arrival rate and processes them into finished goods at a rate of $r$. The finished goods are stored until the end of each cycle and then delivered to the retailer. In the beginning of the following cycle, the finished goods are available for sale at the retailer. The retailer faces uncertain demand and aims to minimize supply-demand mismatches resulting from demand uncertainty. All unmet demand is lost.

Both parties aim to minimize their own costs. They are cost-centric for two reasons. First, perishable products have low profit margins. Second, the substitution rates for perishable products are relatively high, leading to intense competition at brand and store level. The retailer has two decision variables: (1) the replenishment cycle denoted by $T$ and (2) the order quantity denoted by $S$. In the next section, we develop analytical expressions that relates $S$ with $T$. Therefore, we represent $S$ as a function of $T$ (i.e., $S(T)$ ) and remove $S$ from the set of decision variables. The manufacturer has a single decision variable, which is the processing rate (i.e., denoted by $r$ ). Both parties should determine the decision parameters at the beginning of the planning horizon before signing the contract, and those values become fixed in each replenishment cycle.

Both raw materials and finished goods are perishable. The lifetime constraints are tighter for the manufacturer than for the retailer, since fresh product lifetimes are shorter than those of processed products that undergo chemical processes such as dehydration, sterilization and the addition of preservatives such as salt or sugar. We can use the example of fruit juice, composed of highly perishable fruit such as berries. Once the juice is processed, the lifetime will increase due to 
heating or added ingredients that preserve the product.
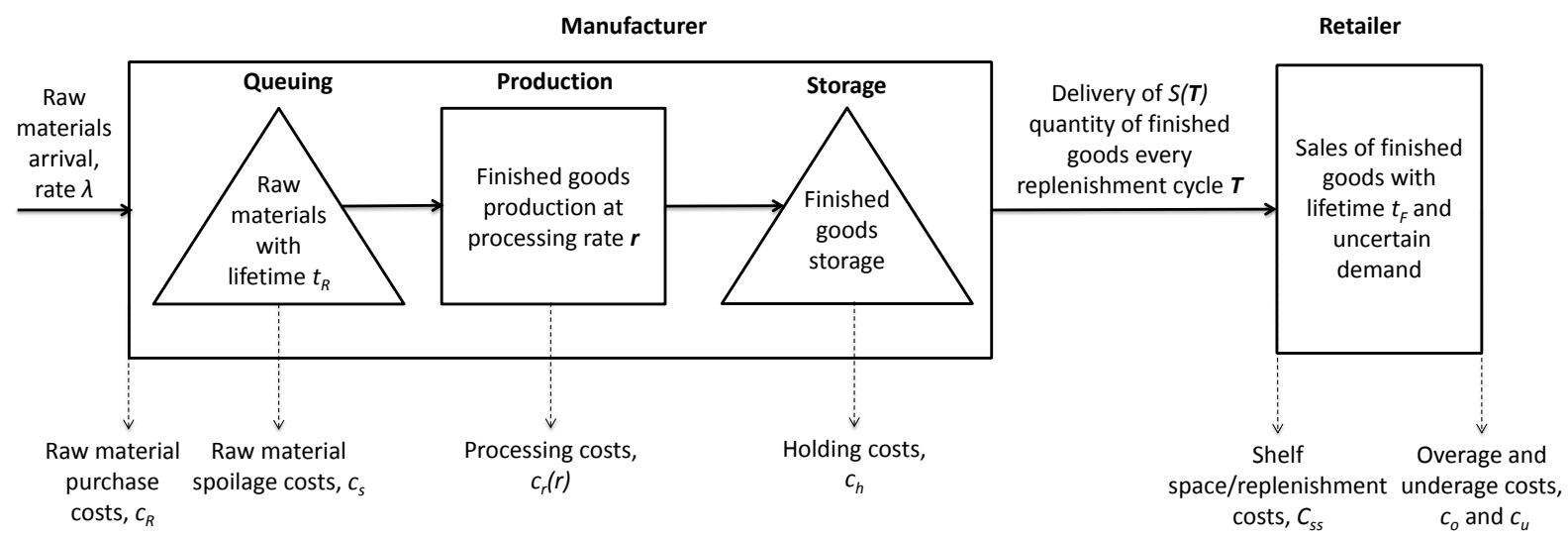

Figure 1. Supply chain of the manufacturer and the retailer

We build our model based on four assumptions:

(1) Raw materials arrive at the manufacturer's factory with a Poisson rate of $\lambda$ and are processed on a first-in-first-out basis with an exponential production rate of $r$. The processing of raw materials is thus represented as a $M / M / 1+D$ queue where $+D$ represents the fixed raw material lifetime denoted by $t_{R}$. Poisson arrivals have been commonly used in the literature for modeling the processing of perishable products such that the arrival rate is determined based on the ripeness of the product (Graves 1982; Gilbert and Ballou 1999; Soman, van Donk, and Gaalman 2004).

(2) There is no delivery lead time for the retailer's orders delivered by the manufacturer. This assumption is supported by Simchi-Levi, Kaminsky, and Simchi-Levi (2009, Chapter 3), where the authors state that direct shipments are prevalent in the grocery industry due to perishability. In our model, production takes place continuously in each cycle. The production time in food supply chains is substantially longer than the delivery lead time. In this paper, we focus on the production lead time while assuming that the delivery lead time is zero.

(3) There is no carryover inventory between replenishment cycles, which causes different product ages in inventory, as explained in Herbon (2017). It is well established in the literature that retailers try to maximize freshness (Amorim, Günther, and Almada-Lobo 2012) and reduce inventory in stores to minimize holding and handling costs (Beamon 1998). Perishable products are generally discounted as the expiry date approaches, or when the store is replenished with newer or fresher products (Tellis and Zufryden 1995; Chew et al. 2014).

(4) The end demand follows a normal distribution. Force-fitting a normal distribution to a de- 
mand dataset may lead to undesirable results such as positive density for negative values of demand and a symmetric distribution around the mean value. However, these problems are more pronounced for higher demand uncertainties (Gallego, Katircioglu, and Ramachandran 2007). Van Donselaar et al. (2006) show that perishables have lower coefficient of variation than durable items. Therefore, the normality assumption is acceptable in our context.

Our model with a continuous production process and periodic replenishment to a retailer is a common practice in food supply chains and capital-intensive industries (Kleindorfer and Wu 2003; Boyabatl, Kleindorfer, and Koontz 2011). In beef supply chains, for example, fed-cattle procurement is managed via long-term contracts, and wholesalers process fed cattle into packaged products and distributes periodically to restaurants and groceries (Boyabatl, Kleindorfer, and Koontz 2011). When the production capacity is limited and the demand is volatile, companies tend to continuously use the limited capacity at a high utilization rate and mitigate the demand risk by reducing the delivery lead time and increasing the replenishment frequency (De Treville et al. 2014; Biçer and Seifert 2017).

In the next sections, we first describe the retailer's problem and the manufacturer's problem separately and then minimize the costs using a Stackelberg system. A list of the notation is given in Table 1.

\section{The Stackelberg model and analytical results}

\subsection{Retailer's cost}

In this section we consider the retailer's problem of reducing mismatch and handling costs (i.e., shelf-space and in-store replenishment costs) for a perishable item when the replenishment cycle is an endogenous parameter. We define the retailer's cost per cycle as the expected value of the sum of mismatch and handling costs. Handling costs for perishable products account for around $300 \%$ of inventory-related costs (Broekmeulen et al. 2004). These types of products should be monitored in retail stores continuously and replaced with newer batches after their due dates. They also require frequent in-store replenishment because they are mostly bulky products.

Our objective is to minimize the retailer's costs by finding the optimal replenishment cycle $T^{*}$ and the corresponding order quantity $S\left(T^{*}\right)$ over the given time horizon $L$. At each replenishment cycle the retailer places orders of $S(T)$ and receives finished products to sell in the following cycle 
from the manufacturer with negligible lead time.

The retailer incurs costs as a result of supply-demand mismatches: If the demand is higher than the available amount of products, the retailer incurs underage costs; otherwise, it incurs overage costs. As explained in the previous section, it is well established that limited shelf-space causes significant costs in retailing (Cachon 2001; Broekmeulen et al. 2004), therefore we include the cost for shelf-space allocated by the retailer for this product, assuming the shelf-space remains fixed throughout the time horizon. We assume that the demand in each replenishment cycle is independent and identically distributed, following a normal distribution with the mean $\mu$ and the standard deviation $\sigma$ as shown in Figure 2. Then, demand for a replenishment cycle of $T$ periods follows a normal distribution:

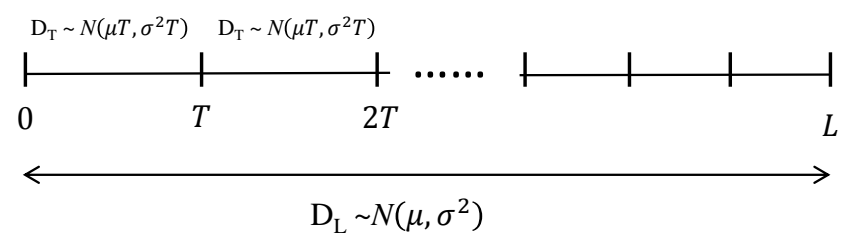

Figure 2. Total demand in the time horizon and periodic demand in a replenishment cycle of duration $T$ where $T \in[0, L]$ and L is normalized to $1 . D_{t}$ and $D_{L}$ represent demand per cycle and in the time horizon, respectively.

The expected value of the sum of mismatch and handling costs (i.e., shelf-space and in-store replenishment costs) per replenishment cycle is formulated as follows:

$$
\begin{aligned}
C\left(S(T) \mid T \leq t_{F}\right)=c_{o}(T) & \int_{0}^{S(T)}(S(T)-x) f(x \mid T) d x \\
& +c_{u}(T) \int_{S(T)}^{\infty}(x-S(T)) f(x \mid T) d x+R(T) .
\end{aligned}
$$

The first term on the right-hand side gives the expected overage cost per period, the second term the expected underage cost, and the last term the average handling costs. Therefore, the sum of the first two terms gives the mismatch costs. The term $x$ represents the demand per replenishment cycle, with $f(x \mid T)$ being the density function with the parameters given in Figure 2. In the classic newsvendor problem, the overage and underage costs do not depend on the replenishment cycle.

The fixed ordering costs are not included our model because the retailer guarantees to the manufacturer a minimum order quantity $S_{\min }$ and the total profit of the manufacturer generated in each cycle is much higher that than fixed ordering cost. The optimal value of $S(T)$ can be significantly larger than $S_{\min }$ because the manufacturers' processing cost as well as the transfer 
price decreases as $S(T)$ increases.

The term $c_{o}(T)=c(r, T)-s$ is the overage cost with sales price $p$ and salvage value $s$. The term $c_{u}(T)=p-c(r, T)$ is the underage cost. The unit cost $c(r, T)$ can be equated as $c(r, T)=g(r, T) \times m$, where $g(r, T)$ is the manufacturer's unit cost and depends on the expected order quantity for the replenishment cycle $T$, while $m$ represents the markup of the manufacturer, based on industry standards. We formulate the term $g(r, T)$ later in Equation 5. The handling cost (i.e., $R(T)$ ) increases with the duration of replenishment cycle (Cachon 2001). We also normalize the planning horizon to one (i.e., $\mathrm{L}=1$ ) by replacing $T$ with $T / L$. When $T=L$, the problem reduces to a single-period newsvendor model.

We apply the change of variables such that $z=\frac{S(T)-\mu T}{\sigma \sqrt{T}}$, where $\Phi(z)$ and $\phi(z)$ represent the standard cumulative distribution and probability density functions for the normal distribution, respectively. The cost per replenishment cycle in Equation 1 can be expressed as follows:

$$
C\left(z \mid T \leq t_{F}\right)=c_{o}(T) \sigma \sqrt{T}(z \Phi(z)+\phi(z))+c_{u}(T) \sigma \sqrt{T}(\phi(z)-z(1-\Phi(z)))+R(T) .
$$

We assume that the shelf-space cost for the total time horizon, represented as $C_{s s} T$, depend on the replenishment cycle due to increasing order quantities in $T$ for the products arriving to the retailer. In practice, $C_{s s} T$ can be found by multiplying the per unit cost of shelf-space, as in Cachon (2001), with the mean demand for the replenishment cycle, $\mu T$. We normalize the total time horizon $L$ to one and scale the length of replenishment cycle $T$ accordingly. Then, the retailer's problem of minimizing the sum of mismatch and handling costs over the total time horizon is found by dividing Equation (2) by $T$ :

$$
\underset{T \leq t_{F}, z_{\min } \leq z}{\operatorname{Minimize}} \bar{C}(z \mid T)=\frac{c_{o}(T) \sigma(z \Phi(z)+\phi(z))}{\sqrt{T}}+\frac{c_{u}(T) \sigma(\phi(z)-z(1-\Phi(z)))}{\sqrt{T}}+C_{s s} T
$$

where $T \in(0,1]$ and $z_{\min }=\frac{S_{\min }-\mu T}{\sigma \sqrt{T}}$. We define a minimum order quantity $S_{\min }$ as the smallest quantity that can be delivered in one replenishment cycle, therefore setting the shortest possible replenishment cycle. As in the retail setting explained in Kırc1, Isaksson, and Seifert (2017), the replenishment frequency and orders for groups of perishables are fixed and frequent, independent of the demand for a single product. However, a minimum delivery quantity is defined with the case size for each product, and the demand determines the delivery frequency per individual product. 
Therefore we use the term $S_{\min }$ to capture the minimum quantities to be delivered in retailing. We also restrict $T<t_{F}$ - that is, the replenishment cycle is limited by the finished goods lifetimeto guarantee service throughout the entire replenishment cycle and ensure product quality and consumer satisfaction. For example, if the product lifetime were 10 and the replenishment cycle 12 days respectively, the product would be unavailable during a 2-day period. For most retailers and products, the constraint $T<t_{F}$ is enforced in two ways. First, days-fresh perishable items are replenished with direct deliveries (Van Woensel et al. 2007) and are mixed with multiple products. Additionally, they are sold with high margins to overcome the high costs due to ordering/transportation and spoilage costs. The second way $T<t_{F}$ is enforced relates to the size of retailer outlets and minimum delivery quantity. Large retailers are usually leaders in their supply chain due to high demand and sales for perishable items. As a result, their products are replenished frequently and rarely expire before sales. For leading retailers, losses due to spoilage and damages combined are as low as 3\% (Buck and Minvielle 2014). This is in line with our model, where the retailer is the leader and $\mu / S_{\min } \approx T<t_{F}$. For smaller retailers, the picture is different. Due to minimum order quantities and case pack sizes (Van Donselaar et al. 2006), small retailers with low total demand for days-fresh perishable items may incur salvage and disposal costs too high to overcome. This will cause them to either eliminate days-fresh perishable items from their product offering, or integrate the cost of spoilage to the sales price.

\subsection{Manufacturer's cost}

On the supply side, the manufacturer uses a make-to-stock policy to satisfy the retailer's orders for the following replenishment cycle. The manufacturer first purchases raw materials from external suppliers at a unit cost of $c_{R}$. The raw materials arrive at the manufacturer's factory at a Poisson arrival rate of $\lambda$, thus we model the raw material arrival and processing as a $M / M / 1+D$ queue where $+D$ represents the deterministic raw material patience, equivalent to its lifetime $t_{R}$. Due to limited production capacity, the raw materials wait at the factory for an expected duration of $W_{q}(r)$ before being processed, where $r$ is the production rate. If arriving raw materials are not processed before $t_{R}$, or in other words if $W_{q}(r)>t_{R}$, the manufacturer incurs a unit spoilage cost of $c_{s}$. Fresh milk or berries are examples of raw materials that deteriorate relatively quickly (within hours or days). We do not consider the costs of idle times and the possibility of spoilage during production in our model. Please note that notation can be found in Table 1. 
We denote by $P\left(W_{q}(r)>t_{R}\right)$, the probability that the raw materials are discarded. We adapt the formulation for impatient customers with deterministic patience given in Barrer (1957), and find the equilibrium spoiled quantity expressed as

$$
P\left(W_{q}(r)>t_{R}\right)=\frac{(r-\lambda) e^{t_{R}(\lambda-r)}}{r\left(1-e^{t_{R}(\lambda-r)}\right)}
$$

Raw materials that are within their $t_{R}$ lifetime limit are sent to production. The total cost of production $c_{r}(r)$ increases linearly with the production rate. The production rate represents the production capacity. We use a linear production cost $c_{r}(r)=a r+b$, with the fixed component $b$ related to rent and storage costs, and variable costs $a$ related to operating costs. For example, increasing the number of shifts of production will increase the variable costs in that replenishment cycle. Linear production costs are commonly used in the literature (Shaw and Wagelmans 1998; Akbalik and Penz 2009).

The objective of the manufacturer is to minimize costs by deciding the optimal balance between spoilage and processing costs. We use the unit cost due to the manufacturer's follower position in the Stackelberg game, and that the cost is conditional to the retailer's replenishment cycle. In the retailer's cost, the unit cost is multiplied with the order size.

The unit cost of processing for one unit in one replenishment cycle is given as $\frac{c_{r}(r)}{S(T)}$. Longer replenishment cycles ensure higher economies of scale at the manufacturer due to the fixed cost of production (i.e., $c_{r}(r)$ ). We use a batch size assumption for the manufacturer such that $S(T)$ is $\mu T$, and that the term $z \sigma \sqrt{T}$ has a sufficiently small impact on the manufacturer's overall cost. Since the average batch size is used, there is a possibility that in some cycles, the full demand might not be met by the manufacturer. This is valid in practical situations, where climate variations or other external factors cause supply issues. In Section 5 we numerically show that the assumption has negligible impacts on the unit cost of the manufacturer.

The manufacturer aims to minimize its expected cost by determining the processing rate that on average produces $S(T)$ units per replenishment cycle. We assume that the manufacturer's output rate is fixed to $S(T)$ although the actual output can be below that amount. If the manufacturer faces any shortfall of raw materials, it can use spot markets to purchase raw materials and guarantee the delivery of $S(T)$ units to the retailer. Spot market purchases in case of yield problems of farmers are common in food supply chains (Boyabatl, Kleindorfer, and Koontz 2011). 
We restrict $r \geq \lambda>\frac{S(T)}{T}$ so that the manufacturer can satisfy the retailer's orders in full in each cycle. The manufacturer's problem of minimizing the unit cost of production is formulated as follows:

$$
\underset{r \geq \lambda>\frac{S(T)}{T}}{\operatorname{Minimize}} g(r, T)=c_{R}+c_{h}+\frac{c_{r}(r)}{S(T)}+\frac{c_{s}(r-\lambda) e^{t_{R}(\lambda-r)}}{r\left(1-e^{t_{R}(\lambda-r)}\right)}
$$

Finally, the manufacturer incurs a unit holding cost of the finished goods, denoted by $c_{h}$. We assume the holding cost is independent of the time the unit is stored within the replenishment cycle. Finished products are sold to the retailer at a price of $g(r, T) \times m$, where $m \in(1, p / g(r, T))$ is an exogenous variable that represents the standard industry markup of the manufacturer's production cost for a given replenishment cycle $T$ and product category, and $p$ is the retailer's selling price.

We use $c_{s}$ to denote the spoilage cost of raw materials per unit. While there are physical costs of disposal, there are also indirect costs that can be considered. Waste is an important key performance indicator in the assessment of firms' environmental performance which leads to lost goodwill or damaged reputation due to increasing consumer awareness for environmental impacts. The manufacturer's objective is to minimize the unit cost. This cost is multiplied by the order quantity in the retailer's cost function in the Stackelberg game. Due to the manufacturer's position in the Stackelberg game as a follower, unit cost minimization is more appropriate for the manufacturer. We formulate the Stackelberg solution in the next section.

\subsection{Stackelberg Game}

We conceptualize our supply chain as a Stackelberg competition with the retailer as the leader and the manufacturer as the follower. In many developed countries, distribution channels and product offerings to end customers are dominated by powerful retailers that have large customer bases. For example, Walmart stores are visited by more than 260 million customers each week, providing the company with strong bargaining power over its suppliers. These types of retailers often squeeze the profits of their suppliers (Riper 2004). Agricultural food products typically have fragmented supply bases, and there is usually no supplier brand awareness at the consumer level. We therefore model the retailer as the leader, and the manufacturer as the follower. We first formulate the manufacturer's best response for all possible replenishment cycle lengths $T$ that the retailer might announce. The manufacturer's cost is given in Equation 5. The proof of convexity of the 
manufacturer's cost in $r$ is given in Appendix B, which guarantees that $r^{*}$ is the global optimum. To find the optimal replenishment cycle, we take the first derivative of $g(r, T)$ with respect to production rate $r$ and set it to zero: $r^{*}=\left\{r \mid \frac{\partial g(r, T)}{\partial r}=0\right\}$. The optimal processing rate $r^{*}$ satisfies

$$
\frac{e^{t_{R}\left(\lambda-r^{*}\right)}\left(\lambda e^{t_{R}\left(\lambda-r^{*}\right)}-\lambda+r^{* 2} t_{R}+r^{*} \lambda t_{R}\right)}{\left(r^{*}-\lambda e^{t_{R}\left(\lambda-r^{*}\right)}\right)^{2}}=\frac{a}{c_{s} S(T)}
$$

where the manufacturer's best response function in terms of $T$ can be found by using Equation 6 in the manufacturer's cost function. The retailer, knowing what the unit cost for the manufacturer would be for each replenishment cycle it suggests, will choose the replenishment cycle $T^{*}$ that minimises it's own costs. The retailer will then feed the unit cost, $g(r, T)$, in it's underage and overage cost terms, $c_{u}(T)$ and $c_{o}(T)$, where $c_{u}(T)=p-m \times g(r, T)$ and $c_{o}(T)=m \times g(r, T)-s$. The optimal unit cost is $g\left(r^{*}\left(T^{*}\right), T^{*}\right)$.

We next find the replenishment cycle that the retailer will set based on the optimal processing rate $r^{*}(T)$ of the manufacturer. We show convexity of the retailer's function in $T$ and detailed solution of the retailer's optimum in Appendix A. We replace $r^{*}(T)$ into the retailer's cost, in the overage and underage costs $c_{o}(T)$ and $c_{u}(T)$. Our objective is to minimize the cost of the retailer, with respect to the replenishment cycle $T$; however, the terms $z=\frac{S(T)-\mu T}{\sigma \sqrt{T}}, c_{u}(T)$ and $c_{o}(T)$ all depend on $T$. We replace $c_{u}(T)$ and $c_{o}(T)$, following a batch size assumption for the manufacturer as explained in Section 4.2.

We follow the methodology introduced in Whitin (1955) and Zabel (1970), and used in Petruzzi and Dada (1999) to use a two-stage optimization in first $z$, then $T$. We show convexity of the Equation 2 with respect to $T$ and $z$ to ensure global optimality of the solution, then substitute $z^{*}$ into the objective function and subsequently optimize $\bar{C}\left(T, z^{*}\right)$ over $T$. It is straightforward from the first derivative with respect to $z$, that the optimal order quantity is identical to the newsvendor solution, shown in Appendix A. We replace the optimal order in Equation 3, which simplifies the cost function to

$$
\bar{C}\left(T \mid z^{*}\right)=\frac{\left(c_{u}+c_{o}\right) \phi\left(z^{*}\right) \sigma}{\sqrt{T}}+C_{s s} T .
$$

where the optimal order quantity $z^{*}$ is dependent on the manufacturer's best response, which is dependent on the optimal processing rate found in Equation 6. By taking the first derivative of the 
retailer's cost $\bar{C}\left(T, z^{*}\right)$ in Equation 7 with respect to $T$, we can show that the optimal replenishment cycle $T^{*}$ satisfies

$$
T^{*}=\left(\frac{2 C_{s s}}{\sigma(p-s) \phi\left(z^{*}\right)}\right)^{2 / 3}
$$

Replacing Equation 8 back into Equation 7 and defining $\xi=\sigma(p-s) \phi\left(z^{*}\right)$, the retailer's minimum cost becomes

$$
\bar{C}\left(z^{*} \mid T\right)=\frac{\xi^{7 / 3}+2 C_{s s}^{4 / 3}}{2 C_{s s}^{5 / 3} \xi^{2 / 3}}
$$

The optimal order quantity becomes $S\left(T^{*}\right)=\mu\left(\frac{2 C_{s s}}{\xi}\right)^{2 / 3}+\sigma z^{*}\left(\frac{2 C_{s s}}{\xi}\right)^{1 / 3}$. If $T^{*}>t_{F}$, then the replenishment cycle is set to $t_{F}$, where

$$
\bar{C}\left(z^{*} \mid T\right)=\frac{\left(c_{u}+c_{o}\right) \phi\left(z^{*}\right) \sigma}{\sqrt{t_{F}}}+C_{s s} t_{F},
$$

and $S\left(T^{*}\right)=\mu t_{F}+z^{*} \sigma \sqrt{t_{F}}$, with $z^{*}$ equal to the newsvendor critical fractile. Note that for $T^{*}$, the minimum unit cost $g\left(r^{*}, T^{*}\right)$ of the manufacturer can be expressed as

$$
g\left(r^{*}, T^{*}\right)=c_{R}+\frac{c_{s} e^{-\left(r^{*}-\lambda\right) t_{R}}}{r^{*}-\lambda e^{-\left(r^{*}-\lambda\right) t_{R}}}\left[r^{*}-\lambda+\left(r^{*}+\frac{b}{a}\right)\left(\frac{\lambda e^{t_{R}\left(\lambda-r^{*}\right)}-\lambda+r^{* 2} t_{R}+r^{*} \lambda t_{R}}{r^{*}-\lambda e^{-\left(r^{*}-\lambda\right) t_{R}}}\right)\right] .
$$

\section{Numerical analysis and discussion}

In this section we conduct a numerical analysis and discuss the managerial implications of our findings. We use the manufacturer's and retailer's costs in Section 4 with a time horizon of 60 days and employ the parameters, shown in Table 2.

Both the manufacturer and retailer's costs are convex, as established in Section 4. The optimal replenishment cycle is 25 days, and the optimal processing rate is 31 units/day. In Figure 3 we illustrate the order quantity per cycle, taking into consideration the minimum order quantity $S_{\min }$ and the finished goods lifetime constraint $t_{F}$. Our aim in Figure 3 is not to optimize for the replenishment cycle but to provide a view of the impact of the replenishment cycle on the order quantity. We observe a linear increase in the order quantity with values close to the mean demand. 
More importantly, in numerical tests the manufacturer's cost remains the same with and without the batch size assumption, which is in line with our approximation for unit processing costs in Appendix B.

Short finished goods lifetimes $t_{F}$, that are lower than the optimal replenishment cycle, result in suboptimal replenishments at the retailer. From a supply chain perspective, there is a repercussion upstream to the manufacturer. Shorter replenishment cycles mean smaller order quantities, which in turn hinders economies of scale for the manufacturer due to the fixed cost of processing. The unit cost of the finished good increases and raises costs for both parties.

Next, we analyze the effect of manufacturer markups to analyze the effect of the intermediate finished goods' selling price on the supply chain costs. From Figure 4, we observe that despite the retailer leading in the Stackelberg game, higher manufacturer markups cause higher mismatch costs for the retailer. This in turn shifts the retailer's cost curve upwards. Contrarily, the manufacturer benefits from longer optimal replenishment cycles that provide for economies of scale. This presents an incentive for the retailer to seize opportunities for integration with the manufacturer.

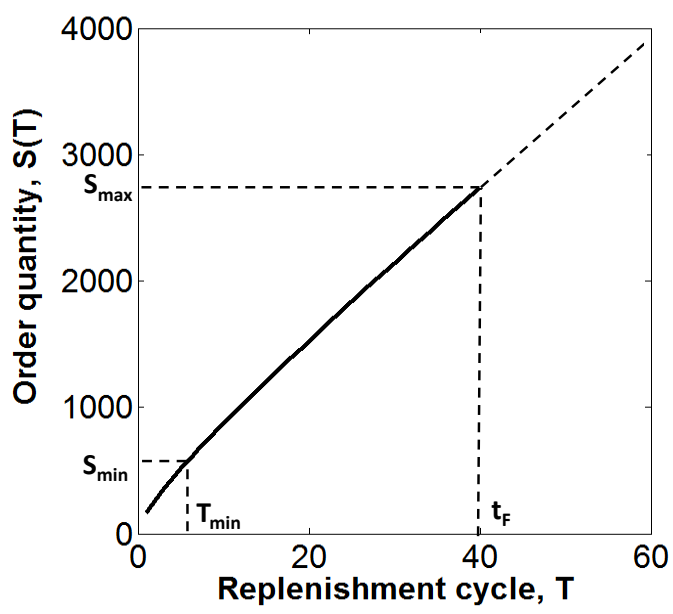

Figure 3. The retailer's order quantity per cycle.

Next, we observe the effect of raw material lifetime on the optimal decision variables, as well as costs for both parties. In Figure 5, we show that the optimal processing rate decreases as the raw materials become more durable. The first point represents the optimal solution when the raw material lifetime is 2 days, and the following points show the results as the lifetime decreases towards 0.1 days. While investments for higher production capacity could decrease spoilage, higher processing rates could increase the fixed cost of production. This tradeoff represents an opportunity 


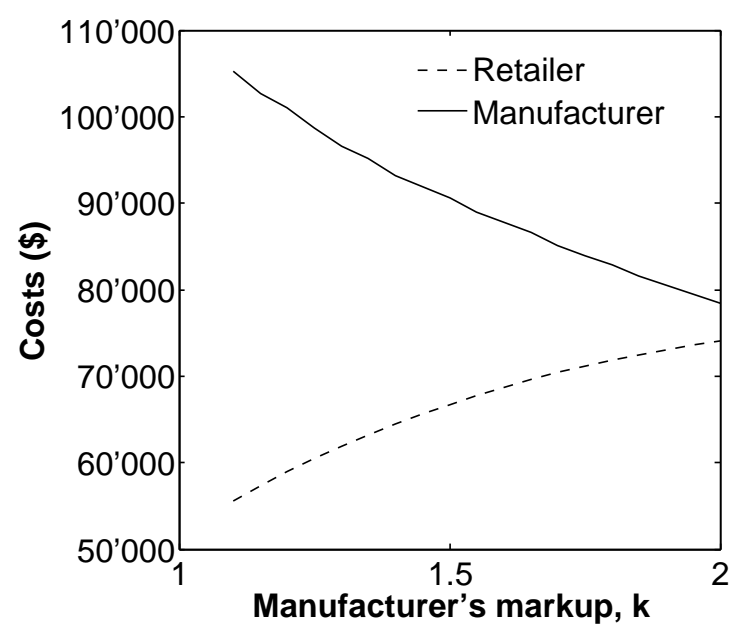

Figure 4. Retailer's costs increase, while the manufacturers' decrease as the markup increases

for future research.

While higher processing rates do not have a very important effect on the optimal replenishment cycle, we observe a significant increase in the manufacturer's costs for short raw material lifetimes, as shown in Figure 6. This is in line with our analytical result in Equation 8, where the optimal replenishment cycle is only influenced by the manufacturer's cost via the critical fractile term $z$. The cost increase for the retailer is due to higher mismatch costs caused by higher manufacturing costs. We conclude that both parties have an incentive to improve raw material lifetime. This is achieved mainly through better agriculture, sourcing, storing and processing practices in the upstream supply chain.

Besides the direct cost impact, indirect impacts of spoilage such as lost goodwill or damaged reputation, which are usually difficult to measure, can also be an important motivation to increase raw material lifetime and reduce spoilage. This should also give manufacturers the incentive to invest in improvements or raw material conditions and quality at the agricultural level. It is already common for leaders in the food industry to collaborate with farmers to increase the quality and lifetime of raw products. Common examples include milk, fruits and vegetables, coffee and cocoa, among others.

High variable costs of processing, $a$, cause an increase in the percentage of the manufacturer's spoilage costs. This finding suggests that operational efficiencies in production such as lower energy and labor costs may also reduce spoilage of raw materials and improve the manufacturer's environmental performance. Furthermore, they cause the manufacturer's cost to be less sensitive to the processing rate above the optimum value. Additionally, we find that high shelf-space costs 


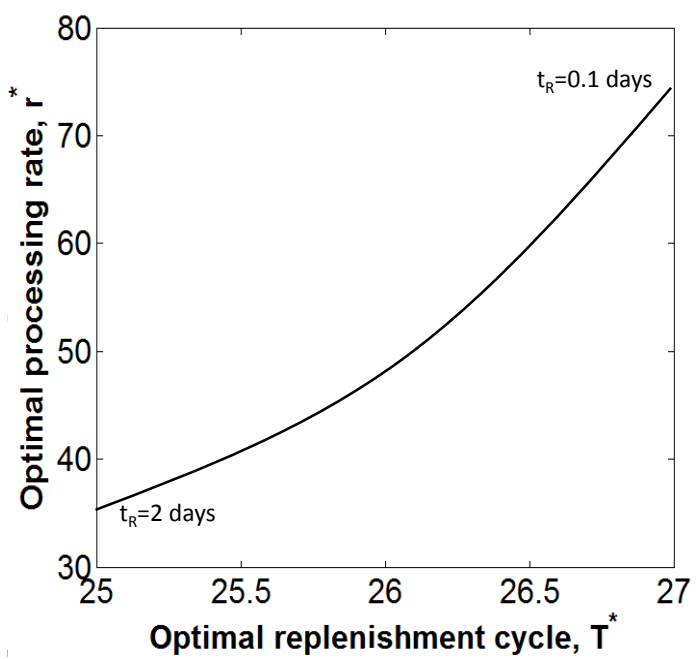

Figure 5. The manufacturer's unit costs are composed of processing and spoilage costs.

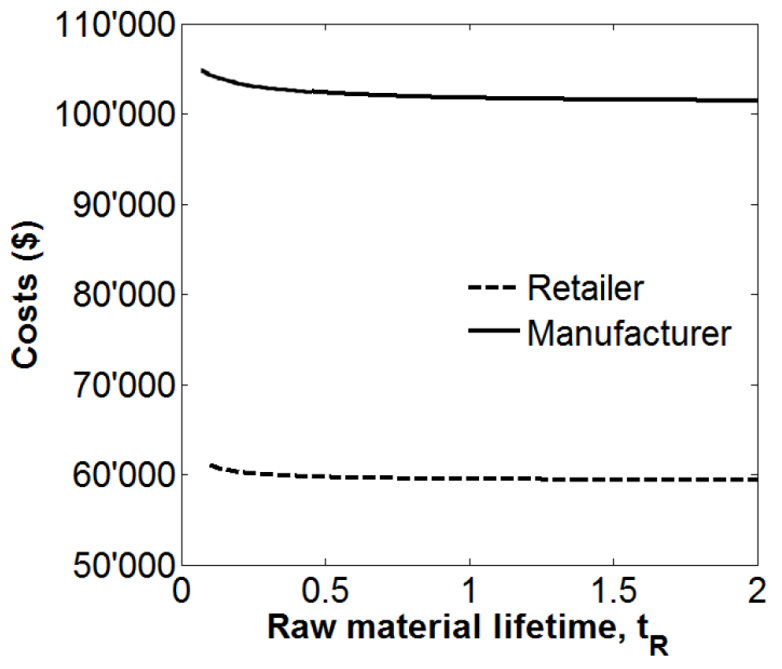

Figure 6. Raw material lifetime increases costs for both parties.

have a negative economic impact for both parties, as shown in Figure 7.

Finally, we discuss the impact of demand volatility on the supply chain costs. High demand volatility increases the costs of the retailer and the manufacturer, with no major change for the manufacturer. This is because the manufacturer delivers the expected order quantity for each replenishment cycle, where the term relating to the mean demand is dominant for manufacturing costs, as in our batch size approximation in Appendix B. 


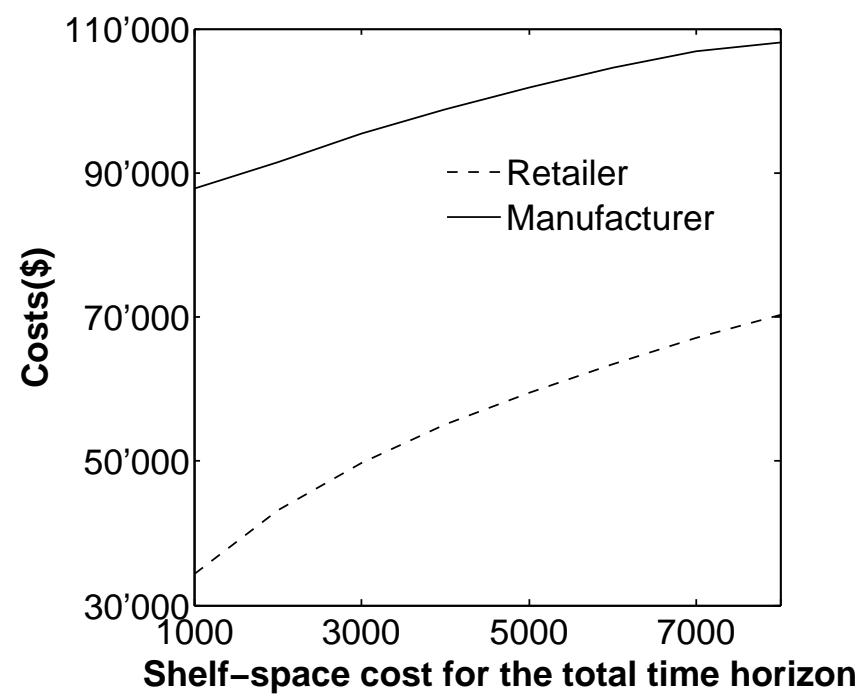

Figure 7. High shelf space costs increases costs for both parties.

\section{Conclusion}

Firms struggle to estimate demand over long time horizons. The costs of demand uncertainty, coupled with the cost of perishability, decrease operational efficiency in a variety of industries. Our paper targets the food industry, in which raw materials such as fresh fruit, vegetables and dairy products are processed into products with a longer shelf life. In the food industry, deciding the optimal replenishment policy through demand forecast updates is important for decreasing costs due to overage and underage. It can also decrease discount or disposal costs for finished products at the retailer. More broadly, firms can improve their environmental impact and reputation by reducing spoilage in their supply chains. In prior literature, Gimenez, Sierra, and Rodon (2012) also found that environmental improvements in manufacturing companies result in better economic performance.

The contribution of this paper is two-fold. First, we model the replenishment cycle as an endogenous variable, whereas previous studies considered the replenishment cycle as an exogenous parameter. We find the analytical solution for the optimal replenishment cycle given demand uncertainty and shelf-space costs. Second, we consider both raw material and finished product perishability in a manufacturer-retailer setting, and quantify the relationship between the two perishability costs. Our paper has implications for both researchers and practitioners working with demand uncertainty for perishable products. 
Our findings give insights on the impact of the perishability of raw materials and finished goods within the supply chain. In what relates to perishability, we summarize three main findings. First, despite spoilage representing relatively low costs, short raw material lifetimes significantly increase both the retailer's and the manufacturer's costs. It is due to the effect of product lifetime on the processing rate and thus the replenishment cycle. Second, we find that higher variable costs in processing increase the raw material spoilage costs. It suggests that efficiencies in production can also improve the environmental performances of manufacturers by reducing raw material spoilage. Third, for finished goods, we find that short lifetimes, or short time limits before the sell-by date, result in more frequent replenishments and higher costs not only for the retailer, but also for the manufacturer. This should create an incentive for manufacturers to produce longer-lasting products, in line with the findings of Amorim, Günther, and Almada-Lobo (2012).

Our model is applicable for perishable product supply chains where decisions are decentralized, the manufacturer and retailer both want to reduce their own costs, and the retailer dominates decisions. This is observed in practice, when distribution channels and product offerings are dominated by powerful retailers that have large customer bases. Such retailers have strong bargaining power over their suppliers. Consequently, manufacturers offer a menu of contracts with different replenishment cycles at competitive transfer prices, often squeezing their profits. For this setting, our solution to the retailer's problem can be applied to determine the replenishment cycle that minimizes its mismatch and shelf-space costs based on the manufacturer's proposals.

There are two main limitations for the application of our model. First, we consider only a single product in a simple two-echelon supply chain. We do not consider the production of other products in the same facility, which would require production scheduling. Second, we do not consider inventory carryover between replenishment cycles at the retailer, but rather discounts for less fresh items, which we represent with salvage costs.

There are many opportunities for future research to enhance the management of perishable products. Future research may integrate seasonality in the demand process and inventory carryover. Another extension might include positive lead times and multiple products or echelons in the supply chain. Additionally, modeling perishability with a G/G/1 queue could increase the applicability of the model.

Research in the area of perishable models in a supply chain context is rare. We thus encourage scholars to pursue empirical studies in this area. Potential future topics might include i) an empirical 
analysis of the impact of finished goods and raw material lifetime on supply chain costs, and ii) quantifying the effect of ordering quantities upstream, on the freshness and spoilage downstream in the supply chain.

\section{References}

Ailawadi, Kusum L., and Bari Harlam. 2004. "An Empirical Analysis of the Determinants of Retail Margins: The Role of Store-Brand Share." Journal of Marketing 68 (1): 147-165.

Akbalik, Aye, and Bernard Penz. 2009. "Exact methods for single-item capacitated lot sizing problem with alternative machines and piece-wise linear production costs." International Journal of Production Economics 119 (2): 367-379.

Amorim, P., H. O. Günther, and B. Almada-Lobo. 2012. "Multi-objective integrated production and distribution planning of perishable products." International Journal of Production Economics 138 (1): 89-101.

Bakker, Monique, Jan Riezebos, and Ruud H. Teunter. 2012. "Review of inventory systems with deterioration since 2001." European Journal of Operational Research 221 (2): 275-284.

Barnes-Schuster, Dawn, Yehuda Bassok, and Ravi Anupindi. 2002. "Coordination and Flexibility in Supply Contracts with Options." Manufacturing 85 Service Operations Management 4 (3): 171-207.

Barrer, D. Y. 1957. "Queuing with impatient customers and ordered service." Operations Research 5 (5): $650-656$.

Beamon, Benita M. 1998. "Supply chain design and analysis: Models and methods." International Journal of Production Economics 55 (3): 281-294.

Biçer, Işık, and Ralf W Seifert. 2017. "Optimal dynamic order scheduling under capacity constraints given demand-forecast evolution." Production and Operations Management 26 (12): 2266-2286.

Boyabatl, Onur, Paul R Kleindorfer, and Stephen R Koontz. 2011. "Integrating long-term and short-term contracting in beef supply chains." Management Science 57 (10): 1771-1787.

Broekmeulen, RACM, K. Van Donselaar, J. Fransoo, and Tom van Woensel. 2004. "Excess shelf space in retail stores: An analytical model and empirical assessment." Beta working paper .

Buck, Raphael, and Arnaud Minvielle. 2014. "A fresh take on food retailing." Perspectives on retail and consumer goods. Winter 2013/2014 71-84.

Cachon, Gerard. 2001. "Managing a retailer's shelf space, inventory, and transportation." Manufacturing \&3 Service Operations Management 3 (3): 211-229.

Cai, Xiaoqiang, Jian Chen, Yongbo Xiao, and Xiaolin Xu. 2010. "Optimization and coordination of fresh product supply chains with freshness-keeping effort." Production and Operations Management 19 (3): 261-278. 
Chew, Ek Peng, Chulung Lee, Rujing Liu, Ki-sung Hong, and Anming Zhang. 2014. "Optimal dynamic pricing and ordering decisions for perishable products." International Journal of Production Economics 157: $39-48$.

Choi, S. Chan. 1991. "Price Competition in a Channel Structure with a Common Retailer." Marketing Science 10 (4): 271-296.

De Treville, Suzanne, Isik Bicer, Valérie Chavez-Demoulin, Verena Hagspiel, Norman Schürhoff, Christophe Tasserit, and Stefan Wager. 2014. "Valuing lead time." Journal of Operations Management 32 (6): $337-$ 346.

Ferguson, Mark E., and Michael Ketzenberg. 2006. "Information Sharing to Improve Retail Product Freshness of Perishables." Production and Operations Management 15 (1): 57-73.

Gallego, Guillermo, Kaan Katircioglu, and Bala Ramachandran. 2007. "Inventory management under highly uncertain demand." Operations Research Letters 35 (3): 281-289.

Gilbert, Stephen M, and Ronald H Ballou. 1999. "Supply chain benefits from advanced customer commitments." Journal of Operations Management 18 (1): 61-73.

Gimenez, Cristina, Vicenta Sierra, and Juan Rodon. 2012. "Sustainable operations: Their impact on the triple bottom line." International Journal of Production Economics 140 (1): 149-159.

Goyal, S. K., and B. C. Giri. 2001. "Recent trends in modeling of deteriorating inventory." European Journal of Operational Research 134 (1): 1-16.

Graves, Stephen C. 1982. "The application of queueing theory to continuous perishable inventory systems." Management Science 28 (4): 400-406.

Gürler, Ülkü, and Banu Yüksel Özkaya. 2008. "Analysis of the (s, S) policy for perishables with a random shelf life." IIE Transactions 40 (8): 759-781.

Gutierrez-Alcoba, Alejandro, Roberto Rossi, Belen Martin-Barragan, and Eligius M. T. Hendrix. 2017. "A simple heuristic for perishable item inventory control under non-stationary stochastic demand." International Journal of Production Research 55 (7): 1885-1897.

Herbon, Avi. 2017. "Should retailers hold a perishable product having different ages? The case of a homogeneous market and multiplicative demand model." International Journal of Production Economics 193 (Supplement C): 479-490.

Huang, Ming-Guan. 2013. "Economic ordering model for deteriorating items with random demand and deterioration." International Journal of Production Research 51 (18): 5612-5624.

Kadiyali, Vrinda, Pradeep Chintagunta, and Naufel Vilcassim. 2000. "Manufacturer-Retailer Channel Interactions and Implications for Channel Power: An Empirical Investigation of Pricing in a Local Market." Marketing Science 19 (2): 127-148.

Karaesmen, Itir Z., Alan Scheller-Wolf, and Borga Deniz. 2011. "Managing perishable and aging inventories: 
Review and future research directions." Planning Production and Inventories in the Extended Enterprise 393-436.

Ketzenberg, Michael, and Mark E. Ferguson. 2008. "Managing slow-moving perishables in the grocery industry." Production and Operations Management 17 (5): 513-521.

Kırc1, Mervegül. 2017. "Improving Firm Performance Through Sustainable Operations (Doctoral Dissertation)." Ecole Polytechnique Fédérale de Lausanne, Lausanne, Switzerland .

Kırc1, Mervegül, Olov Isaksson, and Ralf Seifert. 2017. "Managing perishability in the fresh fruit and vegetable supply chain." Under revision in International Journal of Production Economics .

Kırcı, Mervegül, and Ralf Seifert. 2015. "Dynamic Capabilities in Sustainable Supply Chain Management: A Theoretical Framework." Supply Chain Forum: An International Journal 16 (4): 2-15.

Kleindorfer, Paul R, and Dong J Wu. 2003. "Integrating long-and short-term contracting via business-tobusiness exchanges for capital-intensive industries." Management Science 49 (11): 1597-1615.

Kouki, Chaaben, M. Zied Babai, Zied Jemai, and Stefan Minner. 2016. "A coordinated multi-item inventory system for perishables with random lifetime." International Journal of Production Economics 181 (Part A): $226-237$.

Kummu, M., H. de Moel, M. Porkka, S. Siebert, O. Varis, and P.J. Ward. 2012. "Lost food, wasted resources: Global food supply chain losses and their impacts on freshwater, cropland, and fertiliser use." Science of The Total Environment 438: 477-489.

Minner, Stefan, and Sandra Transchel. 2010. "Periodic review inventory-control for perishable products under service-level constraints." OR Spectrum 32 (4): 979-996.

Nahmias, Steven. 1982. "Perishable inventory theory: A review." Operations Research 30 (4): 680-708.

Nakandala, Dilupa, Henry Lau, and Paul K. C. Shum. 2017. "A lateral transshipment model for perishable inventory management." International Journal of Production Research 55 (18): 5341-5354.

Pasternack, Barry Alan. 1985. "Optimal pricing and return policies for perishable commodities." Marketing science 27 (1): 133-140.

Petruzzi, Nicholas C., and Maqbool Dada. 1999. "Pricing and the Newsvendor Problem: A Review with Extensions." Operations Research 47 (2): 183-194.

Raafat, Fred. 1991. "Survey of literature on continuously deteriorating inventory models." The Journal of the Operational Research Society 42 (1): 27-37.

Reiner, Gerald, Christoph Teller, and Herbert Kotzab. 2013. "Analyzing the Efficient Execution of InStore Logistics Processes in Grocery Retailing — The Case of Dairy Products." Production and Operations Management 22 (4): 924-939.

René, Caldentey, and Lawrence M. Wein. 2003. "Analysis of a Decentralized Production-Inventory System." Manufacturing \& Service Operations Management 5 (1): 1-17. 
Riper, Tom Van. 2004. "The WalMart Squeeze." http : //www.forbes.com/2007/04/23/walmart suppliers - margins - lead - cx_tvr_0423walmart.html.

Savaskan, R. Canan, Shantanu Bhattacharya, and Luk N. Van Wassenhove. 2004. "Closed-Loop Supply Chain Models with Product Remanufacturing." Management Science 50 (2): 239-252.

Shaw, Dong X., and Albert PM Wagelmans. 1998. "An algorithm for single-item capacitated economic lot sizing with piecewise linear production costs and general holding costs." Management Science 44 (6): $831-838$.

Simchi-Levi, David, Philip Kaminsky, and Edith Simchi-Levi. 2009. Designing and Managing the Supply Chain. McGraw-Hill, 3rd edition.

Soman, Chetan Anil, Dirk Pieter van Donk, and Gerard Gaalman. 2004. "Combined make-to-order and make-to-stock in a food production system." International Journal of Production Economics 90 (2): 223235 .

Tellis, Gerard J., and Fred S. Zufryden. 1995. "Tackling the retailer decision maze: Which brands to discount, how much, when and why?" Marketing Science 14 (3): 271-299.

Van Donselaar, K., Tom van Woensel, RACM Broekmeulen, and J. Fransoo. 2006. "Inventory control of perishables in supermarkets." International Journal of Production Economics 104 (2): 462-472.

Van Woensel, Tom, Karel Van Donselaar, Rob Broekmeulen, and Jan Fransoo. 2007. "Consumer responses to shelf out-of-stocks of perishable products." International Journal of Physical Distribution ES Logistics Management 37 (9): 704-718.

Whitin, T. M. 1955. "Inventory Control and Price Theory." Management Science 2 (1): 61-68.

Wu, Ting, Houcai Shen, and Cheng Zhu. 2015. "A multi-period location model with transportation economies-of-scale and perishable inventory." International Journal of Production Economics 169: 343349.

Yu, Yugang, Zhaofu Hong, Linda L. Zhang, Liang Liang, and Chengbin Chu. 2013. "Optimal selection of retailers for a manufacturing vendor in a vendor managed inventory system." European Journal of Operational Research 225 (2): 273-284.

Zabel, Edward. 1970. "Monopoly and uncertainty." The Review of Economic Studies 37 (2): 205-219.

\section{Appendix A. Retailer's optimal solution}

In this section we use the following overage and underage costs: $c_{o}(T)=c(r, T)-s$ and $c_{u}(T)=$ $p-c(r, T)$ to minimize the retailer's sum of mismatch and handling costs over the total time horizon 
as given by Equation (3):

$\underset{T \leq t_{F}, S_{m i n} \leq S(T)}{\operatorname{Minimize}} \bar{C}(S(T) \mid T)=\frac{c_{o}(T)}{T} \int_{0}^{S(T)}(S(T)-x) f(x \mid T) d x+\frac{c_{u}(T)}{T} \int_{S(T)}^{\infty}(x-S(T)) f(x \mid T) d x+C_{s s} T$

Using $z=\frac{S(T)-\mu T}{\sigma \sqrt{T}}$ and the change of variables and $y=\frac{x-\mu T}{\sigma \sqrt{T}}$ we obtain:

$$
\begin{gathered}
\int_{-\infty}^{S(T)}(S(T)-x) f(x \mid T) d x=\sigma \sqrt{T} z \int_{-\infty}^{z} \frac{1}{\sqrt{2 \pi}} e^{-\frac{y^{2}}{2}} d y-\sigma \sqrt{T} \int_{-\infty}^{z} y \frac{1}{\sqrt{2 \pi}} e^{-\frac{y^{2}}{2}} d y \\
=\sigma \sqrt{T} z \Phi(z)+\sigma \sqrt{T} \phi(z) \\
\int_{S(T)}^{\infty}(x-S(T)) f(x \mid T) d x=\sigma \sqrt{T} \int_{z}^{\infty}\left[-\phi^{\prime}(y)\right] d y-z \sigma \sqrt{T} \int_{z}^{\infty} \phi(y) d y \\
=\sigma \sqrt{T}[\phi(z)-z(1-\Phi(z))]
\end{gathered}
$$

Then, our objective function is written as follows:

$$
\bar{C}(z \mid T)=\frac{c_{o}(T) \sigma}{\sqrt{T}}(z \Phi(z)+\phi(z))+\frac{c_{u}(T) \sigma}{\sqrt{T}}(\phi(z)-z(1-\Phi(z)))+C_{s s} T
$$

Our objective is to minimize the cost of the retailer, with respect to the replenishment cycle $T$. Due to the dependency of the terms $z, c_{u}(T)$ and $c_{o}(T)$ on $T$, it is analytically challenging to explicitly replace all terms in the objective function and take the derivative with respect to $T$. Instead, we follow the methodology described in Petruzzi and Dada (1999) and Whitin (1955). We first show convexity of the function with respect to $T$ and $z$ to ensure global optimality of the solution. We check for convexity of Equation A3 in $z$ for a given $T$ by taking the second partial derivative with respect to $z$ and show that it is positive.

$$
\frac{\partial^{2} \bar{C}(z \mid T)}{\partial z^{2}}=\frac{\left(c_{o}(T)+c_{u}(T)\right) \sigma \phi(z)}{\sqrt{T}}>0
$$


We check for convexity of Equation A3 in $T$ for a given $z$ by taking the second partial derivative with respect to $T$,

$$
\frac{\partial^{2} \bar{C}(T \mid z)}{\partial T^{2}}=\frac{(a r+b) m \sigma(3 T+1) z}{2 \mu T^{3} \sqrt{T}}+\frac{3 \sigma\left(c_{o}(T)(z \Phi(z)+\phi(z))+c_{u}(T)(\phi(z)-z(1-\Phi(z)))\right)}{4 T^{2} \sqrt{T}},
$$

and show that the function is positive for $z>0$, where $c_{u}(T)>c_{o}(T)$. Particularly in the case of the grocery industry, such as dairy products that undergo manufacturing and remain perishable, gross margins remain relatively high (Ailawadi and Harlam 2004). This is also consistent with our Stackelberg model where retailers are leaders, and manufacturers are followers.

Given convexity in both $z$ and $T$, we can substitute $z^{*}$ in Equation A3 and consequently solve for $T^{*}$ as introduced in Whitin (1955) and Zabel (1970), and used in Petruzzi and Dada (1999). We first take the partial derivative with respect to $z$, and replace the solution for $z^{*}$ into the original cost function and derive with respect to $T$ to find $T^{*}$. Deriving Equation A3 with respect to $z$ yields the newsvendor critical fractile, with time-dependent unit cost.

$$
\frac{\partial \bar{C}(z \mid T)}{\partial z}=\frac{c_{o}(T) \sigma \Phi(z)}{\sqrt{T}}+\frac{c_{u}(T) \sigma(\Phi(z)-1)}{\sqrt{T}}
$$

From $\phi^{\prime}(z)=-z \phi(z)$, the optimal order-up-to level $S^{*}(T)$ is found by $\partial \bar{C}(z) / \partial z=0$ as in A3, where

$$
\Phi\left(z^{*}\right)=\frac{c_{u}(T)}{c_{u}(T)+c_{o}(T)}
$$

We can therefore find $z^{*}=\Phi^{-1}\left(\frac{c_{u}(T)}{c_{u}(T)+c_{o}(T)}\right)$. Replacing Equation A7 back into Equation A3, the retailer's cost for the optimal order base-stock level becomes

$$
\bar{C}\left(T, z^{*}\right)=\frac{\sigma(p-s) \phi\left(z^{*}\right)}{\sqrt{T}}+C_{s s} T .
$$

Note that the term $c_{o}(T)+c_{u}(T)$ becomes $p-s$, and is independent of $T$. Using the chain rule $\phi(z)=\frac{\partial \Phi(z)}{\partial(z)}$ and taking the first derivative with respect to $\mathrm{T}$, we find

$$
\frac{\partial \bar{C}\left(T, z^{*}\right)}{\partial T}=-\frac{\sigma(p-s) \phi\left(z^{*}\right)}{2 T \sqrt{T}}+C_{s s} .
$$


The optimal replenishment cycle, $T^{*}$ is therefore

$$
T^{*}=\left(\frac{2 C_{s s}}{\sigma(p-s) \phi\left(z^{*}\right)}\right)^{2 / 3}
$$

Note that the term $\frac{\partial \phi\left(z^{*}\right)}{\partial T}=0$ from the chain rule, and the expected order quantity is therefore, $S\left(T^{*}\right)=\mu\left(\frac{2 C_{s s}}{\sigma(p-s) \phi\left(z^{*}\right)}\right)^{2 / 3}+\sigma z^{*}\left(\frac{2 C_{s s}}{\sigma(p-s) \phi\left(z^{*}\right)}\right)^{1 / 3}$, where the optimal value $z^{*}$ is found by Equation A8. Replacing $T^{*}$ back into Equation A3 and defining $\xi=\sigma(p-s) \phi\left(z^{*}\right)$, the retailer's minimum becomes

$$
\bar{C}\left(T^{*}, z^{*}\right)=\frac{\xi^{7 / 3}+2 C_{s s}^{4 / 3}}{2 C_{s s}^{5 / 3} \xi^{2 / 3}} .
$$

\section{Appendix B. Proof of convexity of the manufacturer's cost}

We approximate the expected order quantity to $S(T)=\mu T$ for the manufacturer only, and call it a batch size assumption that the term $z \sigma \sqrt{T}$ has a sufficiently small impact on the manufacturer's overall cost. In Section 5 we numerically show that the assumption has negligible impacts on the overall optimum order quantity and replenishment cycle. Our numerical results also show that our approximation does not cause a significant change for the optimum. We can now show that the retailer's cost is convex in $\mathrm{T}$, since $\frac{\partial^{2} g(r \mid T)}{\partial T^{2}}=\frac{2(a r+b)}{\mu T^{3}}>0$.

The second derivative of $P\left(W_{q}(r)>t_{R}\right)$ with respect to $\mathrm{r}$ is positive, and the first two terms of the objective function and the constraint are all linear, conserving convexity for $r \geq \lambda$. This condition is naturally satisfied since the queue length approaches infinity when the service rate is less than or equal to the arrival rate. Therefore the problem is convex and the solution is a global minimum. 
3. Tables

\begin{tabular}{|c|c|c|}
\hline Notation & Denotation & Comments \\
\hline \multicolumn{3}{|l|}{ Retailer } \\
\hline$L$ & Time horizon & $L=N \times T$ \\
\hline$\mu$ & Mean demand over L & \\
\hline$\sigma$ & Standard deviation of demand over L & \\
\hline$T$ & $\begin{array}{l}\text { Replenishment cycle, time interval between two re- } \\
\text { plenishments }\end{array}$ & \\
\hline$S$ & Order quantity & \\
\hline$C_{s s}$ & Shelf-space cost for the total time horizon & \\
\hline$R(T)$ & Shelf-space cost per replenishment cycle & \\
\hline$p$ & Unit price of the product & \\
\hline$s$ & Salvage value of the finished product & \\
\hline$\phi$ & Probability density function & \\
\hline$\Phi$ & Cumulative density function & \\
\hline$C$ & Mismatch cost for a single replenishment cycle & \\
\hline $\bar{C}$ & Total mismatch cost over the time horizon & \\
\hline$g(r, T)$ & Manufacturer's cost of producing one unit & \\
\hline$m$ & $\begin{array}{l}\text { Standard industry markup of the manufacturer's pro- } \\
\text { duction cost }\end{array}$ & \\
\hline$c_{u}$ & Cost of underage & $c_{u}(T)=p-m \times g(r, T)$ \\
\hline$c_{o}$ & Cost of overage & $c_{o}(T)=m \times g(r, T)-s$ \\
\hline$t_{F}$ & $\begin{array}{l}\text { Minimum finished-good shelf-life constraint given by } \\
\text { retailer }\end{array}$ & \\
\hline$S_{\text {min }}$ & Minimum order quantity & \\
\hline$c(r, T)$ & $\begin{array}{l}\text { Buying price of the retailer, equal to the manufac- } \\
\text { turer's cost multiplied by the markup }\end{array}$ & $c(T)=g(r, T) \times m$ \\
\hline \multicolumn{3}{|l|}{ Manufacturer } \\
\hline$t_{R}$ & Raw material lifetime & \\
\hline$\lambda$ & Raw material arrival rate & \\
\hline$r$ & Production rate & \\
\hline$W_{q}(r)$ & Raw material waiting time & \\
\hline$c_{R}$ & Unit raw material cost & \\
\hline$c_{h}$ & Manufacturer's holding cost per unit & \\
\hline$c_{r}(r)$ & Processing cost per cycle & $c_{r}(r)=a r+b$ \\
\hline$a$ & Variable operating cost & \\
\hline$b$ & Fixed cost related to rent and storage & \\
\hline$c_{s}$ & Raw material spoilage and disposal cost & \\
\hline
\end{tabular}

3. Tables

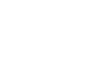

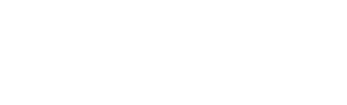




\begin{tabular}{|c|c|c|c|}
\hline & Parameter & Denotation & Set value \\
\hline & $L$ & Time horizon & 60 days \\
\hline & $\mu$ & Mean demand over L & 3000 \\
\hline & $\sigma$ & Standard deviation of demand over $\mathrm{L}$ & 1000 \\
\hline & $C_{s s}$ & Shelf-space cost for the total time horizon & $\$ 5000$ \\
\hline & $p$ & Unit price & $\$ 100$ \\
\hline & $s$ & Salvage value of finished goods & $\$ 10$ \\
\hline & $S_{\text {min }}$ & Minimum order quantity & 500 \\
\hline & $c_{R}$ & Unit raw material cost & $\$ 20$ \\
\hline & $c_{h}$ & Manufacturer's holding cost & $\$ 2$ \\
\hline & $c_{r}(r)$ & Processing cost per cycle & $\$(30 \mathrm{r}+300)$ \\
\hline & $c_{s}$ & Cost of spoilage for raw materials & $\$ 25$ \\
\hline & $m$ & Manufacturer's markup & 1.2 \\
\hline & $\lambda$ & Raw material arrival rate & 30 units/day \\
\hline & $t_{R}$ & Raw materials lifetime & 1 day \\
\hline & $t_{F}$ & Finished goods lifetime & 40 days \\
\hline
\end{tabular}

Table 2. Parameter inputs for numerical model

.

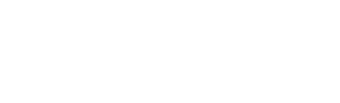




\section{Figure captions}

Figure 1: Supply chain of the manufacturer and the retailer.

Figure 2: Total demand in the time horizon and periodic demand in a replenishment cycle of duration $T$ where $T \in[0, L]$ and $\mathrm{L}$ is normalized to $1 . D_{t}$ and $D_{L}$ represent demand per cycle and in the time horizon, respectively.

Figure 3: The retailer's order quantity per cycle.

Figure 4: The retailer's costs increases, while the manufacturers' decreases as the markup increases. Figure 5: The manufacturer's unit costs are composed of processing and spoilage costs.

Figure 6: Raw material lifetime increases costs for both parties.

Figure 7: High shelf space costs increases costs for both parties. 